\title{
Osteoma and Ectopic Tooth of the Left Maxillary Sinus: A Unique Coexistence
}

\author{
Ümit Aydın, Burak Aşık, Asif Ahmedov, Abdullah Durmaz
}

Department of Otolaryngology, Head and Neck Surgery, Gülhane Military Medical Academy, Ankara, Turkey

Background: Ectopic eruption of a tooth or osteoma rarely occurs within the maxillary sinus. Coexistence of these two rare entities in the maxillary sinus has never been reported in the English literature.

Case Report: Herein, we present a 21 year-old male patient with osteoma and ectopic tooth in the left maxillary sinus treated with the removal of the ectopic tooth by endoscopic sinus surgery and excision of the osteoma by the CaldwellLuc procedure.

Conclusion: Unique coexistence of two different entities in the maxillary sinus is most likely due to pediatric facial trauma. Pediatric patients with maxillofacial trauma should be carefully watched for dental injury both clinically and radiologically.

Keywords: Ectopic tooth, maxillary sinus, osteoma
Osteomas are benign, slow-growing tumors of the bone and consist of mature compact or cancellous bone (1). These are the most common benign tumors of paranasal sinuses (1). The most common region is frontal sinus (1). Maxillary sinus is a rare localization for osteoma (1). Ectopic teeth are located in areas other than the alveolar arch and are infrequently seen in the maxillary sinus (2). To the best of our knowledge, this paper is the first to present the combination of two rare entities within the maxillary sinus. We also discussed the possible etiologic factors and surgical management.

\section{CASE PRESENTATION}

A 21 year-old male presented with the complaints of pain and feeling of pressure, especially during biting over the left cheek for the past two months. He had a history of sinus infection not responding to antibiotics in this period. In detailed medical history, the patient mentioned a maxillofacial injury due to falling down at the age of ten which was treated with debridement and suturing of wounds. Intraoral examination showed that the upper third molar was absent and the patient had a small draining oro-antral fistula in this location
(Figure 1). Endoscopic nasal examination of the nasal cavity showed normal nasal mucosa. The remainder of the examinations were also within normal limits. An orthopantomogram was initially performed for the missing upper left third molar, which showed that the ectopic third molar was located just above a radiopaque mass in the left upper jaw (Figure 2).In order to determine the exact location of the ectopic third molar and radiopaque mass, computed tomography (CT) of the paranasal sinuses was performed. In the coronal cross-section, a fully developed ectopic third molar and underlying hyperdense mass were seen in the left maxillary sinus. The welldefined mass under the ectopic third molar was $15 \times 25 \mathrm{~mm}$ in size and compatible with the compact bone. This osseous mass was located in the inferior portion of the maxillary sinus and near the alveolar arch (Figure 3 ). The left maxillary sinus volume was increased and nasal septum was deviated to the right side. The ectopic third molar was adjacent to the posterior maxillary sinus wall and orbital floor, but CT revealed no involvement. The other part of the left maxillary sinus was completely opacified by the soft tissue density which is consistent with sinusitis. Preoperative biopsy of the osseous mass was not needed since there was no clinical sign of malignancy and imaging findings were highly suggestive of osteoma. 


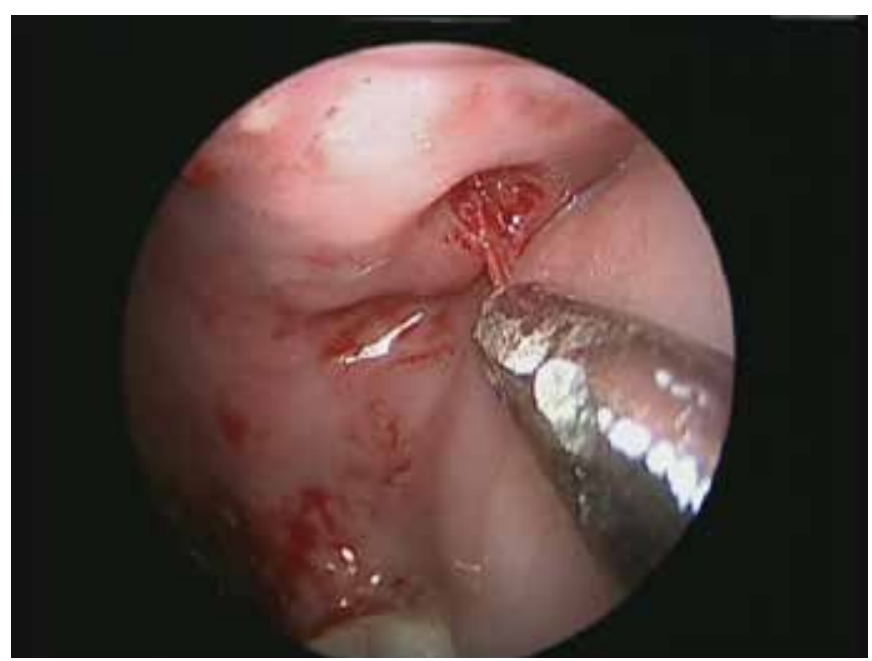

FIG. 1. Mucous discharge draining from the small orontral fistula in the left upper molar region

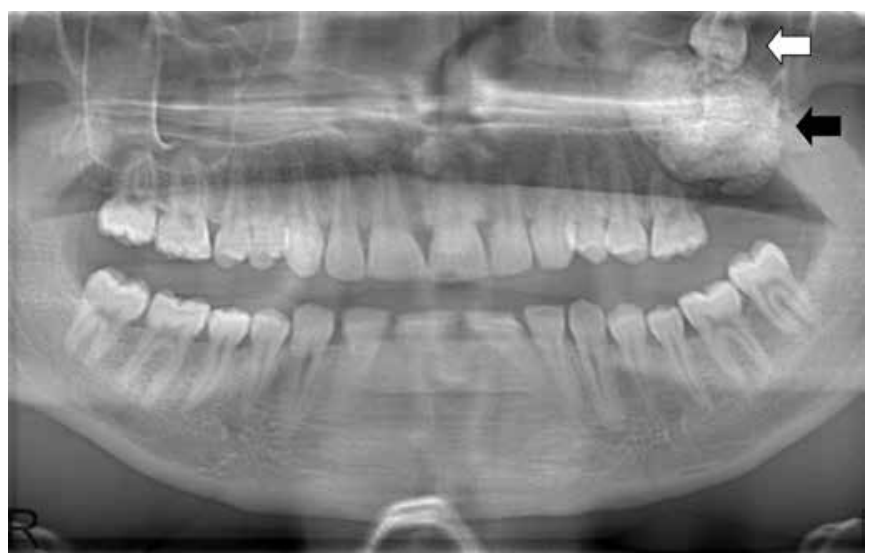

FIG. 2. Orthopantomogram reveals the missing third molar (white arrow) and radiopaque mass (black arrow) in the left upper jaw.

The patient was admitted for surgical intervention under general anesthesia. We initially performed endonasal endoscopic uncinectomy and maxillary antrostomy to reveal the ectopic tooth (Figure 4a). There was an eggshell-like bony cover over the tooth (Figure $4 \mathrm{~b}$ ). The ectopic third molar was clearly observed after the removal of this cover. The tooth was closely related to the orbital floor and posterior maxillary wall, so that it was carefully dissected from these structures (Figure $4 c$ ) and extracted from the maxillary antrum (Figure 4d). The patient then underwent the Caldwell-Luc procedure to excise the osseous mass. Subsequently, primary suturation was preferred for the repair of oroantral fistula due to small fistula opening. The histopathologic diagnosis of osseous lesion was osteoma. The postoperative period was uneventful except for the second repair with a buccal flap for recurrent oroantral fistula. The patient was completely relieved from the complaints following the second surgery. Written informed consent was also obtained from the patient who participated in this paper.

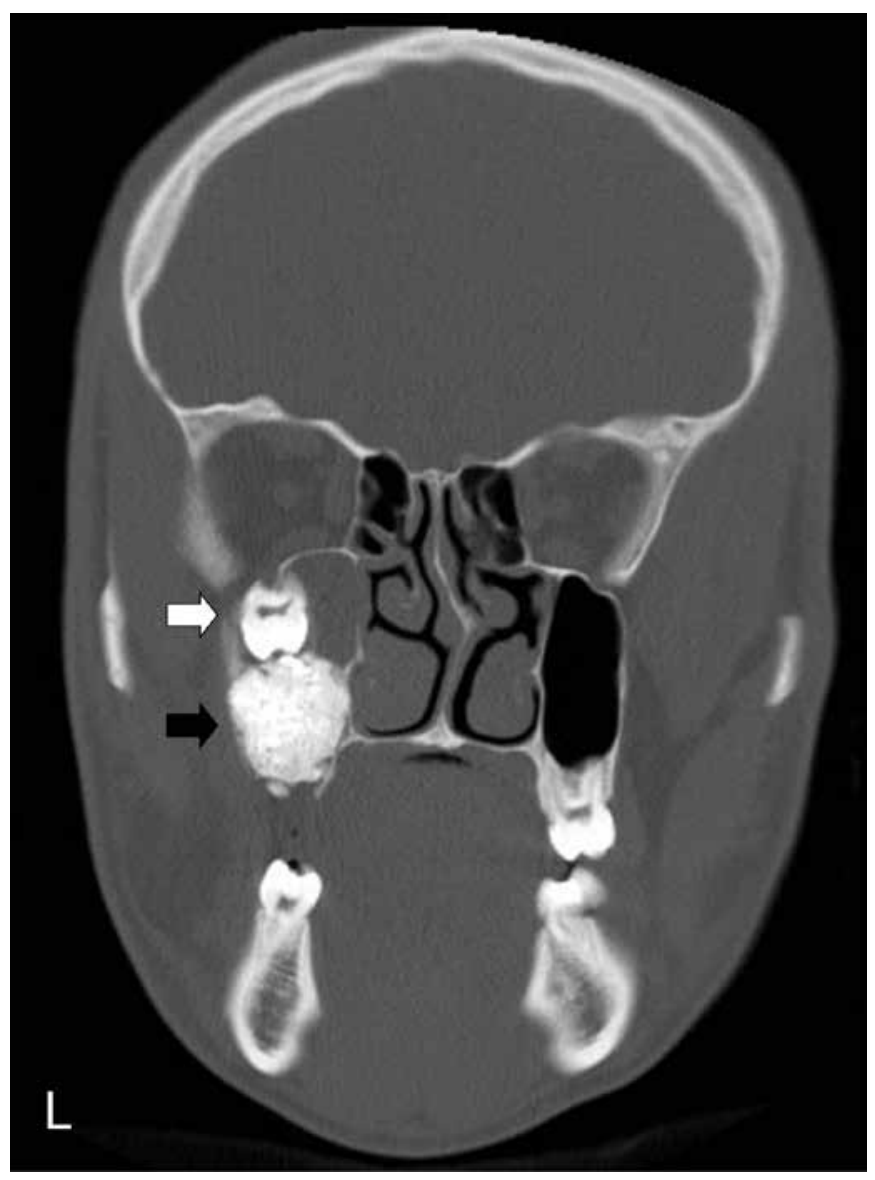

FIG. 3. Coronal CT scan of the paranasal sinuses depicts the ectopic third molar (white arrow) and bony mass (black arrow) in the left maxillary sinus

\section{DISCUSSION}

Osteomas are the most common fibro-osseous lesion of the paranasal sinuses (1). Various theories (traumatic, infectious and developmental) have been proposed for the pathogenesis of the paranasal sinus osteomas $(3,4)$. Trauma to the bone may cause a reactive osteogenic process which activates growth of bone formation. Chronic inflammation may induce the bone turnover that cause the abnormal development of bone. Stimulation of embriyological remnants has also suggested for osteoma formation (5). Moretti et al. (4) suggested that trauma along with the irritative stimulus of the chronic inflammation may generate an osteogenetic process which leads to the formation of osteoma. However, the exact pathogenesis of the osteoma is still unclear. A long period of latency of the clinical symptoms usually makes difficult the assessment of the casueeffect relationship (5).

Asymptomaytic and small osteomas may not require surgical intervention and observed with the periodic radiological imaging (6). Koivunen et al. (6) reported that paranasal sinus 

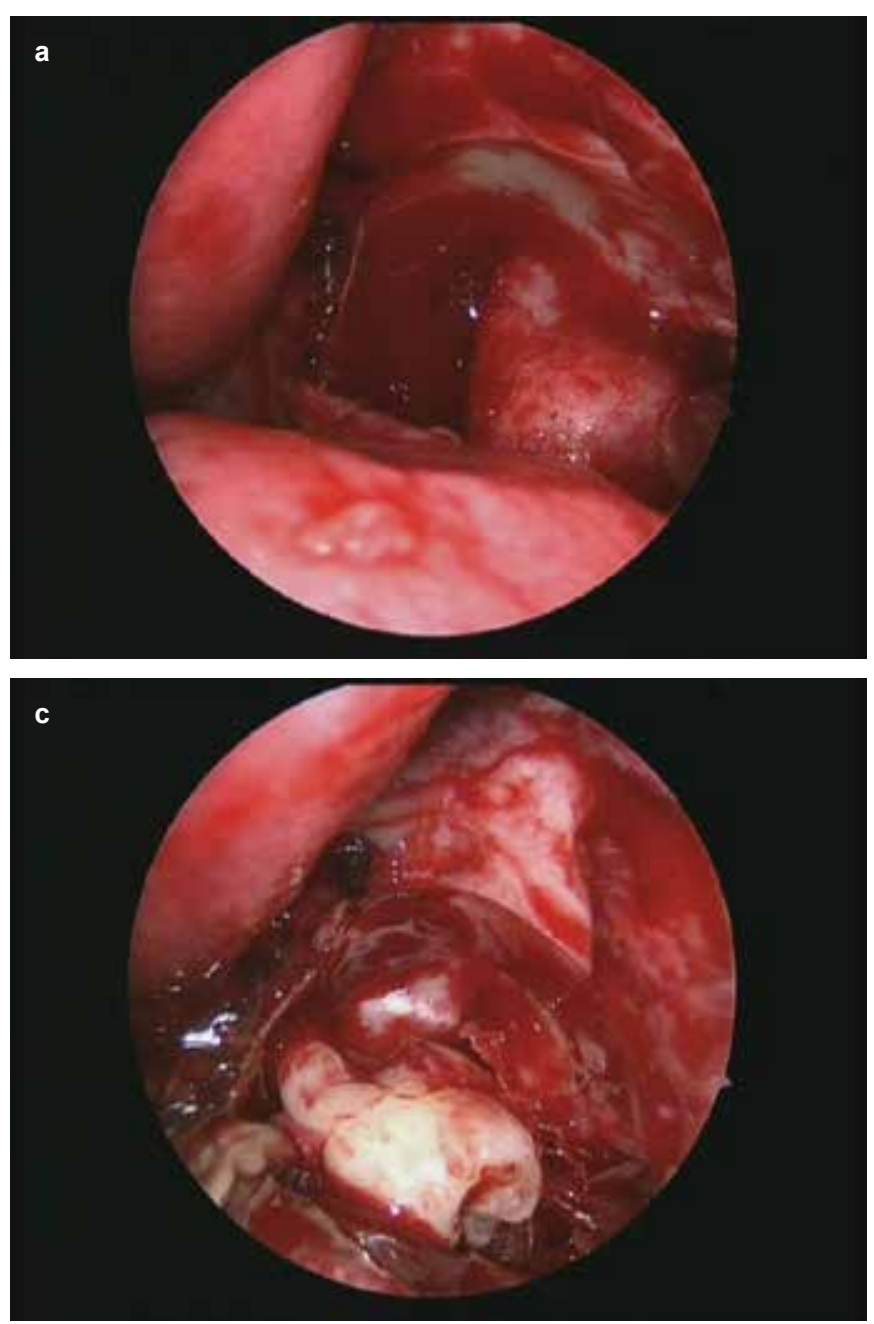
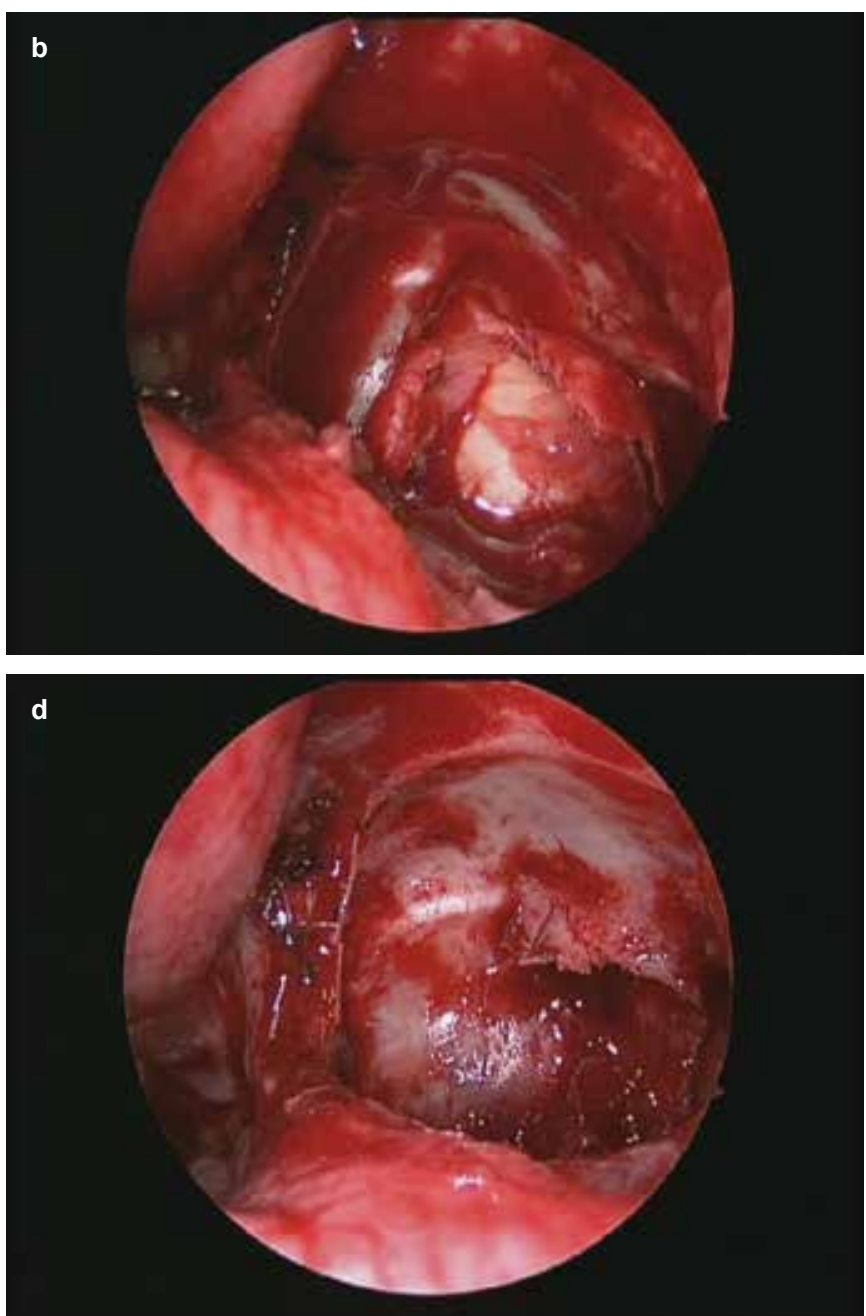

FIG. 4 a-d. Intraoperative endonasal endoscopic views of the removal of ectopic 3rd molar from the maxillary antrum. Ectopic 3rd molar in the left maxillary sinus revealed after the large maxillary antrostomy (a), an egg-shell like bony cover removed from over the tooth (b), the ectopic tooth dislocated from the maxillary sinus walls (c), and the tooth removed via maxillary ostium (d).

osteomas should be removed when the mass lesion fills $50 \%$ of the sinus volume. The surgical procedure depends on the location, extent and existing complications (1). Maxillary sinus osteoma which is large in size and located in the inferior part of the maxillary sinus can be excised with the Caldwell-Luc procedure (1). Osteomas located in the upper part of the maxillary sinus can also be treated endoscopically (1). If surgery is needed, it should be the conservative removal of the lesion without damage to the surrounding structures (1).

Ectopic eruption of a tooth within the dentate region is often seen in clinical practice, which is more common in the mandible. Ectopic tooth eruption in a non-dental area such as the maxillary sinus, nasal cavity and mandibular condyle rarely occurs. The primary teeth begin to form in utero at about six weeks with the development of maxillar and mandibular dental lamina. Afterwards, ectodermal layer proliferation stimu- lates the formation of the permanent dentition. Teeth evolution is associated with an interaction between the oral epithelium and the underlying mesenchymal tissue. A number of factors that disrupt this interaction may result in ectopic tooth development and eruption (7). These are maxillofacial trauma, previous odontogenic or rhinogenic infection, developmental anomalies like cleft palate and pathologic conditions such as cyst or tumor (8). However, the exact etiology often remains unclear. Litvin et al. (2) reported a case where the displacement of tooth by the expansion of the dentigerous cyst leads to the ectopic eruption of tooth in the maxillary sinus. Ectopic eruption of teeth following trauma to the primary and permanent dentitions also reported in literature (9).

The presence of ectopic tooth in the maxillary sinus is often asymptomatic in most of the cases and generally noticed incidentally. Radiopaque image of the ectopic tooth eas- 
ily detected with panaromic radiography (8). CT is essential for the definite diagnosis, exact location of the ectopic tooth and proper treatment planning (8). The third molar tooth is the most affected (8). Ectopic tooth in the sinus occasionally causes symptoms of recurrent sinusitis following the ostial obstruction (8). An asymptomatic ectopic tooth can be observed without treatment. The treatment of a symptomatic ectopic tooth in maxillary sinus requires the removal of the tooth by Caldwell-Luc procedure (2). Transnasal endoscopic removal of an ectopic tooth in maxillary sinus may be tried when the tooth is small and located close to maxillary ostium (10).

We tried to explain the pathogenesis of the unique coexistence in this case given the etiologic factors for ectopic tooth and osteoma formation in the paranasal sinuses. Two possible scenarios appeared in the common etiology for osteoma and ectopic tooth, although it is difficult to establish a specific cause-effect relationship. We consider first that the osteoma formation in the maxillary sinus at close proximity to the alveolar arch may cause migration of the third molar tooth into the maxillary sinus and may result in ectopic eruption. However, the fact that our patient had a maxillofacial trauma history suggested to us a second theory. A pediatric maxillofacial trauma might cause the eruption of the tooth and resultant reactive osteogenic process and chronic inflammation might activate the growth of bone to osteoma formation in the maxillary sinus. In our opinion, the ectopic third molar tooth, osteoma, maxillary sinusitis and oroantral fistula along with the history of trauma strongly support the second scenario. We preferred the combined approach for surgical treatment. An ectopic third molar tooth is initially removed via transnasal endoscopy and the subsequent osteoma by the Caldwell-Luc procedure.

Pediatric maxillofacial traumas can cause displacement and developmental anomalies of the tooth which may result in ectopic eruption of a tooth in the maxillary sinus. Then, reactive osteogenic process and chronic inflammation within the sinus could lead to osteoma formation in the following period (5). Therefore, pediatric patients with maxillofacial trauma should be carefully watched for dental injury, both clinically and radiologically (9). The treatment for osteoma and an ectopic tooth within the maxillary sinus is surgical excision. CT findings are essential for choosing the appropriate surgical procedure.

\section{Ethics Committee Approval: N/A.}

Informed Consent: Written informed consent was obtained from patient who participated in this study.

Peer-review: Externally peer-reviewed.

Author contributions: Concept - Ü.A.; Design - A.D.; Supervision - A.D.; Data Collection and/or Processing - B.A.; Analysis and/ or Interpretation - B.A.; Literature Search - A.A.; Writing - Ü.A.; Critical Reviews - A.D.

Conflict of Interest: No conflict of interest was declared by the authors.

Financial Disclosure: The authors declared that this study has received no financial support.

\section{REFERENCES}

1. Çelenk F, Baysal E, Karata ZA, Durucu C, Mumbuç S, Kanlıkama M. Paranasal sinus osteomas. J Craniofac Surg 2012;23:433-7. [Crossref]

2. Litvin M, Caprice D, Infranco L. Dentigerous cyst of the maxilla with impacted tooth displaced into orbital rim and floor. Ear Nose Throat J 2008;87:160-2.

3. Larrea-Oyarbide N, Valmaseda-Castellon E, Berini-Aytes L, Gay-Escoda C. Osteomas of the craniofacial region: review of 106 cases. J Oral Pathol Med 2008;37:38-42. [Crossref]

4. Moretti A, Croce A, Leone O, D'Agostino L. Osteoma of maxillary sinus: case report. Acta Otorhinolaryngol Ital 2004;24:219-22.

5. Aldren CP, Soames JV, Birchall JP. J Bony remodelling in an osteoma of the paranasal sinuses. J Laryngol Otol 1993;107:633-5. [Crossref]

6. Koivunen $\mathrm{P}$, Löppönen $\mathrm{H}$, Fors AP, Jokinen K. The growth rate of osteomas of the paranasal sinuses. Clin Otolaryngol Allied Sci 1997;22:111-4. [Crossref]

7. Srinivasa Prasad T, Sujatha G, Niazi TM, Rajesh P. Dentigerous cyst associated with an ectopic third molar in the maxillary sinus: A rare entity. Indian J Dent Res 2007;18:141-3. [Crossref]

8. Lamb JF, Husein OF, Spiess AC. Ectopic molar in the maxillary sinus precipitating a mucocele: a case report and literature review. Ear Nose Throat J 2009;88:6-11.

9. Gilbride MJ, Smith WP. Br Dent J. Eruption of teeth in the nose following trauma to the primary and permanent dentitions. $\mathrm{Br}$ Dent J 2005;26;198:199-2. [Crossref]

10. Viterbo S, Griffa A, Boffano P. Endoscopic removal of an ectopic tooth in maxillary sinus. J Craniofac Surg 2013;24:46-8. [Crossref] 